University of Nebraska - Lincoln

DigitalCommons@University of Nebraska - Lincoln

Agronomy \& Horticulture - Faculty Publications

Agronomy and Horticulture Department

July 2003

\title{
Evaluating SHOOTGRO 4.0 as a potential winter wheat management tool in the Czech Republic
}

Z. Zalud

Mendel University of Agriculture and Forestry Brno

G.S. McMaster

USDA-ARS

Wallace Wilhelm

University of Nebraska-Lincoln, wwilhelm1@unl.edu

Follow this and additional works at: https://digitalcommons.unl.edu/agronomyfacpub

Part of the Plant Sciences Commons

Zalud, Z.; McMaster, G.S.; and Wilhelm, Wallace, "Evaluating SHOOTGRO 4.0 as a potential winter wheat management tool in the Czech Republic" (2003). Agronomy \& Horticulture -- Faculty Publications. 23. https://digitalcommons.unl.edu/agronomyfacpub/23

This Article is brought to you for free and open access by the Agronomy and Horticulture Department at DigitalCommons@University of Nebraska - Lincoln. It has been accepted for inclusion in Agronomy \& Horticulture -Faculty Publications by an authorized administrator of DigitalCommons@University of Nebraska - Lincoln. 


\title{
Evaluating SHOOTGRO 4.0 as a potential winter wheat management tool in the Czech Republic
}

\author{
Z. Žalud ${ }^{\mathrm{a}, *}$, G.S. McMaster ${ }^{\mathrm{b}, 1}$, W.W. Wilhelm ${ }^{\mathrm{c}, 2}$ \\ ${ }^{a}$ Institute of Landscape Ecology, Mendel University of Agriculture and Forestry Brno, Zemědělská 1, CZ-613 00 Brno, Czech Republic \\ ${ }^{\mathrm{b}}$ USDA-ARS, Great Plains Systems Research, Room 353, 301 S. Howes St., Fort Collins, CO 80521, USA \\ ${ }^{\mathrm{c}}$ USDA-ARS, Soil and Water Conservation Research, 117 Keim Hall, University of Nebraska, Lincoln, NE 68583, USA
}

Received 16 May 2001; received in revised form 5 November 2002; accepted 18 November 2002

\begin{abstract}
Improving current cultural practices often involves more precise timing of the management activity based on crop development. Using crop simulation models to predict crop development and phenology has several problems. First, most existing models do not simulate sufficient developmental and phenological detail required to optimize selected management practices. Second, crop models normally emphasize the cultivars and conditions for the region in which they were developed, and may not generate satisfactory results when applied in new regions. Lastly, when users apply these models to new regions they often lack the specific data and knowledge of the model to adequately determine the crop parameters. Our objective was to assess whether the simulation model SHOOTGRO 4.0, which had the necessary level of developmental and phenological detail required for use as a management decision aid, could be easily and adequately parameterized to simulate winter wheat phenology and grain yield in the Czech Republic. We found that only a few parameters from the generic winter wheat cultivar used for the Central Great Plains in the USA needed to be changed, and the information needed to determine these few parameters were readily obtainable. The result was that the dates of anthesis and physiological maturity and final grain yield were predicted well at sites within the three major crop production regions of the Czech Republic. Sensitivity analysis also showed that the most sensitive management practices and initial conditions in SHOOTGRO are relatively easy to determine (e.g. sowing date, $\mathrm{N}$ fertilizer rate and timing, daily temperature), while it is not overly sensitive to those variables more difficult to determine (e.g. initial soil water in the profile). Based on this study, farmers and scientists needing wheat development information to increase the efficacy of their management practices can use SHOOTGRO 4.0 as a tool.
\end{abstract}

(C) 2003 Elsevier Science B.V. All rights reserved.

Keywords: Winter wheat; Crop model; Validation; Phenology; Yield

* Corresponding author. Tel./fax: +4205-4513-3083.

E-mail addresses: zalud@mendelu.ez (Z. Žalud), greg. mcmaster@ars.usda.gov (G.S. McMaster), wwilhelm1@unl. edu (W.W. Wilhelm).

1 Tel.: +1-970-490-8340.

2 Tel.: +1-402-472-1512.

\section{Introduction}

The development of precision agriculture coupled with the recognition that many management practices need to be supported by real-time crop development and phenological information is 
resulting in increased interest in using crop simulation models as, or as part of, decision aids. Efforts to optimize planting dates and rates, select cultivars, forecast harvest dates, and increase the efficacy of management practices involving herbicides, fertilizers (especially split application practices), and irrigation have underscored the need for accurate predictions of crop development to aid in these decisions. The approach is to maximize the desired plant response by optimizing the timing of the management practice at the critical growth stage(s) for determining yield. As our understanding of wheat (Triticum aestivum L.) development has increased, many developmental events occurring at the shoot apical meristem such as single and double ridges, terminal spikelet, beginning of internode elongation, and appearance of the flag leaf have been identified as critical in determining yield potential (McMaster, 1997).

Over 70 models predicting wheat yield were identified in 1993 (McMaster, 1993), and the number has grown substantially since. Many of these models have been used to examine the impact of certain management practices (e.g. N fertilizer rates, planting dates, harvest date) on yield with current or changed climate conditions (e.g. Iglesias, 1995; Moot et al., 1996; McMaster and Wilhelm, 1997a; Wolf, 1993; Žalud, 1999; Dubrovský et al., 2000). Most of these models would be characterized as carbon- or energydriven models, and developmental and phenological detail has not been emphasized. As a result, with management practices increasingly focused on finer resolution of developmental and phenological detail, these models are of limited use for these applications.

A few mechanistic models, such as SHOOTGRO (McMaster et al., 1991, 1992a,b; Wilhelm et al., 1993), MODWht (Rickman et al., 1996), AFRCWHEAT (Weir et al., 1984), and SIRIUS (Jamieson et al., 1998), incorporate considerable developmental and phenological detail. These models address the need for greater resolution in simulating development to aid optimizing management practices. SHOOTGRO and MODWht predict development and growth of the canopy and subsequent yield by using temperature, the primary factor controlling wheat development
(McMaster, 1997), to simulate developmental events occurring at or near the shoot apical meristem (e.g. leaf, tiller, spikelet, and floret primordium initiation and growth). This approach provides a complete picture of all sources and sinks present in the canopy at any time and a thorough (realistic) representation of the distribution of developmental stages of all shoot apices comprising the entire canopy.

An older version of the SHOOTGRO model (version 2.0) showed promise in simulating phenology of all growth stages for a range of conditions and cultivars in the Central Great Plains of the United States (McMaster et al., 1992b). The current unpublished version (4.0) has incorporated the effects of water and $\mathrm{N}$ stress on phenology, which should allow SHOOTGRO to better predict wheat phenological responses to management practices and, therefore, aid in optimizing these practices.

Developmentally-driven models, such as SHOOTGRO, MODWht, AFRCWHEAT, and SIRIUS, expand the suite of existing models available to users for different purposes, but two problems in adapting these models, and all models, still must be addressed: parameterizing and evaluating them for conditions and cultivars outside of their region of development. Almost all simulation models were developed within a few countries or regions (US, Western Europe, Australia, and New Zealand) for their conditions and cultivars. Users from other countries where conditions and cultivars differ must first determine what is needed to adequately parameterize the model for their situation, and then evaluate the model predictions under the new conditions. Occasionally, partial sensitivity analysis is performed to evaluate the importance of selected inputs and parameters on output, but rarely do these analyses explore the mechanisms for the model response.

Our objective was to assess whether the simulation model SHOOTGRO 4.0, which had the necessary level of developmental and phenological detail required for use as a management decision aid, could be easily and adequately parameterized to simulate winter wheat phenology and grain yield in the Czech Republic. To achieve this objective, we validated the previously untested 
modifications to the phenology submodel of version 2.0 and yield prediction. We also conducted sensitivity analyses to assess the value of more accurate parameter estimation or inputs than was done for our limited parameterization and examine model sensitivity and response to certain management practices (e.g. planting date and amount, $\mathrm{N}$ fertilizer amount and timing) and environmental conditions (e.g. temperature, initial soil water) in predicting winter wheat phenology and yield.

\section{Materials and methods}

\subsection{SHOOTGRO 4.0 overview}

SHOOTGRO 4.0 is a phenologically driven model that simulates development and growth of the shoot apex of wheat and barley (Hordeum vulgare L.) for up to six cohorts (or age classes) of plants based on the time of seedling emergence. The appearance, growth (both size and weight), and abortion/senescence of each leaf blade and sheath, node, internode and spike component (spikelet, floret, kernel, rachis, and floral bracts) on each morphologically identified leaf, culm, and spike component (Klepper et al., 1983; Wilhelm and McMaster, 1996) are simulated for each age class. Model output includes the date each culm of each age class reaches each growth stage or shoot apex developmental event and summaries of developmental and physiological processes such as organ size (length, width, biomass), yield, yield components, tiller and spike number, LAI, and $\mathrm{N}$ concentration in each plant component or culm. The CERES-Wheat (Ritchie and Otter, 1985) soil water and $\mathrm{N}$ submodels are used and require initial soil conditions for each layer such as bulk density, $\mathrm{pH}$, organic $\mathrm{C}$, initial soil water content, $\mathrm{NO}_{3}$, and $\mathrm{NH}_{4}$ concentrations. Daily meteorological variables required are maximum and minimum temperature, precipitation, and solar radiation.

For wheat and barley, temperature is the primary factor controlling development (McMaster, 1997). Thermal time is used to determine developmental rates. Growing degree-days (GDD) are used to estimate thermal time using
Method 1 of McMaster and Wilhelm (1997b) and the base temperature is set to $0{ }^{\circ} \mathrm{C}$ (McMaster, 1997; McMaster and Smika, 1988). Rather than using static estimates of GDD for thermal time requirements for developmental and growth processes, SHOOTGRO bases many processes on the phyllochron, or rate of leaf appearance. The phyllochron is calculated at the time of seedling emergence of each cohort from the change in day length using the equation of Baker et al. (1980), which was the most accurate of nine equations available for calculating the phyllochron for winter wheat (McMaster and Wilhelm, 1995).

SHOOTGRO 4.0 has been changed from SHOOTGRO/SPIKEGRO 2.0 (McMaster et al., 1991, 1992a,b; Wilhelm et al., 1993) in several ways. Simulating spring wheat and spring barley has been added as well as an algorithm for simulating rooting depth based on GDD accumulation. Most importantly for this manuscript, the effects of water and $\mathrm{N}$ stress on phenology were incorporated. Version 2.0 used only thermal time for estimating growth stages. However, for wheat and barley, phenological growth stages are reached earlier under water and $\mathrm{N}$ stress once a threshold level of the stress is achieved (e.g. McMaster, 1997; McMaster and Smika, 1988; McMaster et al., 2002). Therefore, the phenology submodel was modified so that once the water and $\mathrm{N}$ resource $0-1$ index factors (multiplied together) were less than 0.8 , the required phyllochrons (or GDD) were linearly reduced until a maximum of $20 \%$ reduction was achieved.

\subsection{Crop production regions of Czech Republic}

Wheat is grown in three crop production regions within the Czech Republic. These regions are characterized by different climates, topographies, and primary crops (Table 1). Maize (Zea mays L.) is the primary crop grown in Region 1 (Žabčice, southern part of the Moravia region) with Oxyaquic Cryofluvent soils with topsoils of clay loam and silty clay textures. Sugar beet (Beta vulgare L.) is the primary crop grown on loam soils (Luvi Haplic Chernozem) of Region 2 (Kroměříž, the Upper-Moravian region). Region 3 (Domanínek, Bohemian-Moravian Uplands) is the potato (So- 
Table 1

Characteristics of the experimental fields located in the three crop production regions of the Czech Republic

\begin{tabular}{llll}
\hline Characteristic & Site 1 & Site 2 & Site 3 \\
\hline Location & Žabčice & Kroměříž & Domanínek \\
Latitude & $49^{\circ} 01^{\prime} \mathrm{N}$ & $49^{\circ} 18^{\prime} \mathrm{N}$ & $49^{\circ} 32^{\prime} \mathrm{N}$ \\
Longitude & $16^{\circ} 37^{\prime} \mathrm{E}$ & $17^{\circ} 23^{\prime} \mathrm{E}$ & $16^{\circ} 15^{\prime} \mathrm{E}$ \\
Elevation $(\mathrm{m})$ & 179 & 234 & 560 \\
Primary crop & Maize & Sugar beet & Potato \\
Soil type & Qxyaqic & Luvi Haplic & Cambisol with \\
& Cryofluvents & Chernozem & sandy-loam \\
Mean annual temperature $\left({ }^{\circ} \mathrm{C}\right)$ & 9.2 & 8.6 & 6.5 \\
Mean temperature (April-September, $\left.{ }^{\circ} \mathrm{C}\right)$ & 15.7 & 15.1 & 12.8 \\
Mean annual precipitation $(\mathrm{mm})$ & 480 & 599 & 651 \\
Mean precipitation (April-September, mm) & 312 & 389 & 396 \\
Range of annual accumulated global radiation $\left(\mathrm{MJ} \mathrm{m}^{-2}\right)$ & $3584-4312$ & $3601-4228$ & $3213-3843$ \\
\hline
\end{tabular}

Meteorological data were collected from 1961 through 1990.

lanum tuberosum L.) production region with Cambisol sandy loam soils that have three diagnostic horizons. Elevation and precipitation increase and temperature decreases from Region 1 to 3. SHOOTGRO 4.0 was evaluated for one site in each region.

\subsection{Setting up SHOOTGRO 4.0 for simulation runs}

Setting up SHOOTGRO 4.0 for simulation runs requires that appropriate crop parameters are selected for the cultivar, the initial conditions at the beginning of the simulation are set, and the required driving variables and inputs are provided. Methods for data collection related to initial conditions and driving variables are provided in Section 2.4.1 (Model validation). Four soil layers were used in the simulation $0-0.3,0.3-0.6,0.6-$ 0.9 , and $0.9-1.8 \mathrm{~m}$.

To assist in setting crop parameters, generic meteorological and pedologic data files were created to aid in crop parameterization and for sensitivity analysis. Temperature and precipitation data were measured from 1961 through 1990 at each field site. Global radiation was partly obtained by measurements using a CM 6B pyranometer (WMO first class standard, produced by
Kipp and Zonen company, Delft Holland ${ }^{3}$ ) and partly computed for Site 1 (Rožnovský and Svoboda, 1995), Site 2 (Střalková et al., 1998), and Site 3 (Trnka, 1999). To create the generic meteorological data sets for each region, long-term temperature, precipitation, and global radiation means were used from the above data.

Little information was available for the cultivar Hana, so parameters for a generic winter wheat plant (derived for US cultivars) were used for most crop parameters. To modify the phenological parameters, the typical planting date and day of jointing, anthesis, and physiological maturity for each site was estimated by agronomists from the Czech Republic Agricultural Office. Then using the generic weather files, thermal time between growth stages was calculated using Method 1 of McMaster and Wilhelm (1997b) and base temperature was set to $0{ }^{\circ} \mathrm{C}$ (McMaster, 1997; McMaster and Smika, 1988). Other growth stages (e.g. tiller initiation, single and double ridge, terminal spikelet, beginning of internode elongation, booting, heading) were based on the typical relationships found for wheat cultivars (McMaster, 1997). The only other parameters modified

\footnotetext{
3 Product names are mentioned for information purposes and do not represent endorsement by the authors or USDA.
} 
were the rates of spikelet and floret primordium initiation so that the maximum final number of simulated spikelets per spike and florets per central spikelet equated the observed values based on the opinion of agronomists from the Czech Republic Agricultural Office.

\subsection{Model evaluation}

Model evaluation consisted of two components: validation and sensitivity analysis.

\subsubsection{Model validation}

Wheat is grown in all three crop production regions of the Czech Republic. To validate SHOOTGRO 4.0 for the diverse production regions, meteorological, pedological, crop, and management data were collected from an experimental field in each crop production region (Table 1). Experimental methods followed the official methodology for the field trials outlined by the Czech Central Institute for Supervision and Testing and were under its constant supervision.

One field trial for each region was conducted in 1998-1999, using the semi-dwarf, hard-red winter wheat cultivar Hana at each of the three sites. The experimental design was a randomized complete block, with four replications. Treatments at each location consisted of previous crop (barley or alfalfa, Medicago sativa L.), planting date (two dates at each site; Site 1: 258 and 281 day of year (DOY); Site 2: 259 and 274 DOY, Site 3: 277 and 282 DOY), planting rate (250 or 400 seeds per $\mathrm{m}^{2}$ ), and nitrogen fertilizer rate and timing $(40 \mathrm{~kg} \mathrm{~N}$ $\mathrm{ha}^{-1}$ applied in autumn or $40 \mathrm{~kg} \mathrm{~N} \mathrm{ha}{ }^{-1}$ applied in autumn and $80 \mathrm{~kg} \mathrm{~N}$ ha $^{-1}$ applied in the spring).

An automated meteorological station was used to collect daily weather data at the field trial at Site 1. Meteorological data for the field trials at Sites 2 and 3 were collected by a World Meteorological Organization (WMO) standard meteorological station. Pedological parameters such as bulk density, organic carbon, lower limit of plant extractable water, drained upper limit, saturated water content, and bare soil albedo were obtained from soil cores at planting or direct measurements at each experimental site. Soil cores used for these assays were collected to $1.8 \mathrm{~m}$ and divided into 0.1 $\mathrm{m}$ sections for analysis. Other soil parameters such as $\mathrm{pH}, \mathrm{NO}_{3}$, and $\mathrm{NH}_{4}$ were based on long-term means for each site. The date when $2 / 3$ of the culms reached anthesis (Zadoks growth stage 61; Zadoks et al., 1974) and physiological maturity were based on daily observations of $0.5 \mathrm{~m}^{2}$ in each plot (about 325 spikes per plot). Physiological maturity was determined as the complete loss of green color in all spike components. Yield measurements were obtained by plot combine.

Four statistics were used to evaluate simulation results: (1) paired $t$-test to determine if differences existed between observed and simulated values; (2) simple linear regressions were computed to determine the $r^{2}$-value between observed and simulated data; (3) percentage of predicted dates plus or minus 7 days of the observed growth stage date or percentage of simulated yields plus or minus $20 \%$ of the observed yield; and (4) root mean square error (RMSE), with associated sum of the residuals (SRES) and sum of the absolute residuals (SARES) as described by McMaster et al. (1992b). The RMSE, SRES, and SARES measures give an indication of the variability around the mean and tendency for prediction bias.

\subsubsection{Sensitivity analysis}

Sensitivity analysis evaluated model grain yield and phenological responses to selected management practices and environmental conditions. A unique weather file based on long-term temperature, precipitation, and solar radiation for each site was created. Parameters or model inputs were increased and decreased by specified increments over a broad range and corresponding model phenological responses (emergence, first tiller, initiation of stem elongation, jointing, booting, heading, anthesis, and physiological maturity) and crop growth characteristics (grain yield, above ground biomass, harvest index, number of culms and spikes, and LAI) noted.

Phenological parameters for the thermal time between growth stages were varied by 50 GDD (for grain filling duration) or 0.1 phyllochrons (for all other growth stage intervals). Planting date was varied by 5 days, sowing rate by 50 seeds per $\mathrm{m}^{2}$, daily maximum and minimum air temperature 
decreased and increased by $1{ }^{\circ} \mathrm{C}$ increments until altered by -4 and $+4{ }^{\circ} \mathrm{C}$, and fall $\mathrm{N}$ fertilizer by $5 \mathrm{~kg} \mathrm{~N} \mathrm{ha}^{-1}$ increments beginning with no fertilizer and ending at $85 \mathrm{~kg} \mathrm{~N}^{-1}$. The timing of $\mathrm{N}$ fertilizer application was based on three possible application times with each application time applying $40 \mathrm{~kg} \mathrm{~N} \mathrm{ha}^{-1}$ for Sites 1 and 2 and $45 \mathrm{~kg} \mathrm{~N} \mathrm{ha}^{-1}$ for Site 3 . The first application time was pre-sowing in the fall [DOY 271, 273, and 282 for Sites 1-3, respectively] and two application times in the spring. The early spring application time was DOY 55, 64, and 104, respectively, and the late application time was DOY 110, 125, and 139 for Sites 1-3, respectively. Initial soil water content for the profile was simulated for three levels designated 'low' (decreasing the 'medium' levels by 10\%), 'medium' (determined by 'normal' levels typically observed at the time of planting, and 'high' (equal to field capacity water content).

From the variety of sensitivity indices available we chose the following sensitivity index based on Deer-Ascough (1995):

$S=\left(\frac{O_{\text {base }}-O_{\mathrm{i}}}{O_{\text {base }}}\right) /\left(\frac{I_{\text {base }}-I_{\mathrm{i}}}{I_{\text {base }}}\right)$

where $S$ is the sensitivity index for the specific variable, $I_{\text {base }}$ is the default or initial value for the specific input variable about which it is changed, $I_{\mathrm{i}}$, is the specific value of the input variable that is incremented from $I_{\text {base }}, O_{\text {base }}$ is the output variable value for the $I_{\text {base }}$ input, and $O_{\mathrm{i}}$ is the output variable value for the $I_{\mathrm{i}}$ input.

The sensitivity index was calculated for each incremental change in the input variable tested $(=$ $I_{\mathrm{i}}$ ), and the associated $O_{\mathrm{i}}$ used in the equation listed above. We chose grain yield and date of emergence, jointing, anthesis, and physiological maturity as the output variables.

\section{Results and discussion}

\subsection{Validation}

Regardless of the measure used to assess the simulation accuracy of SHOOTGRO in predicting anthesis and physiological maturity (RMSE, $r^{2}$, paired $t$-test, or percentage of points within some error estimate), SHOOTGRO was able to simulate the date of anthesis and physiological maturity well for each site in all three regions, with equal prediction accuracy for all sites. The SRES and SARES indicated no model bias towards predicting anthesis and physiological maturity earlier or later. Maturity was predicted slightly better than anthesis regardless of measure used for this analysis (number of points within 7 days, RMSE, $r^{2}$, or paired $t$-test).

The phenological simulation results are encouraging that SHOOTGRO can be useful in predicting growth stages in the Czech Republic with little effort needed to parameterize the model. In our evaluation work, parameterization of phenological parameters of SHOOTGRO consisted of using only the general dates of jointing, anthesis, and maturity of generic wheat cultivars in each production region obtained from agronomists familiar with the region. The successful results of this are denoted by open diamond symbols falling on the 1:1 line in Figs. 1 and 2. This suggests that SHOOTGRO can be used to predict phenological growth stages for specific cultivars with readily available information, and therefore, assist in optimizing management decisions.

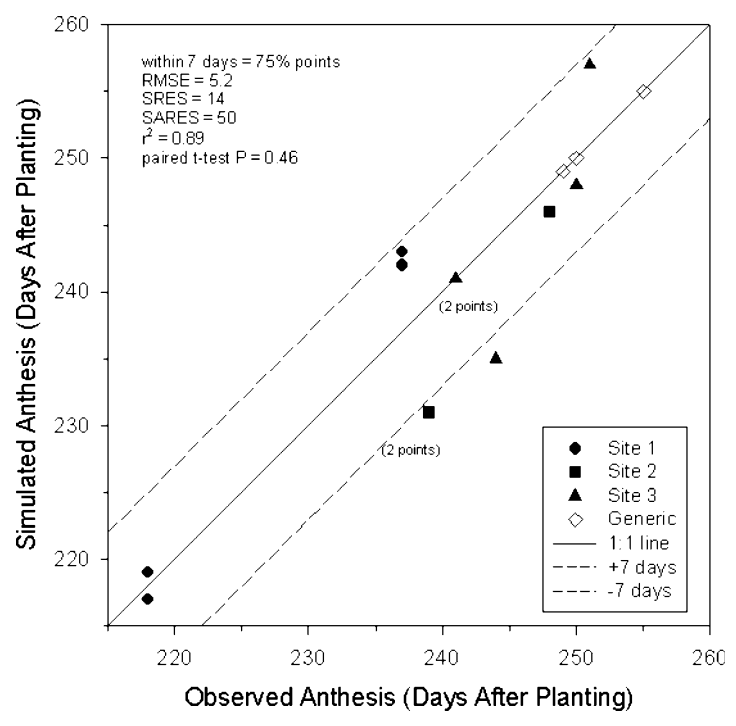

Fig. 1. Observed vs. simulated day of anthesis. 


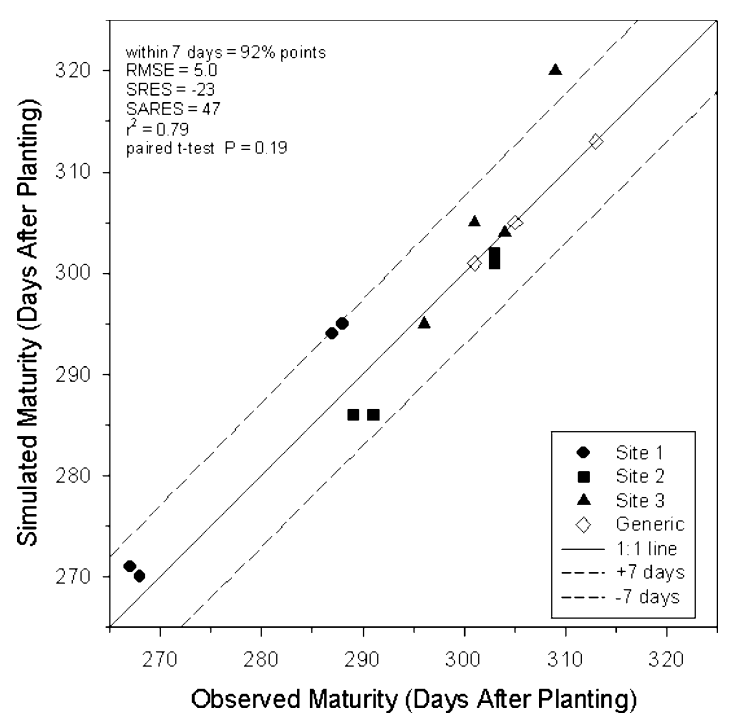

Fig. 2. Observed vs. simulated day of physiological maturity.

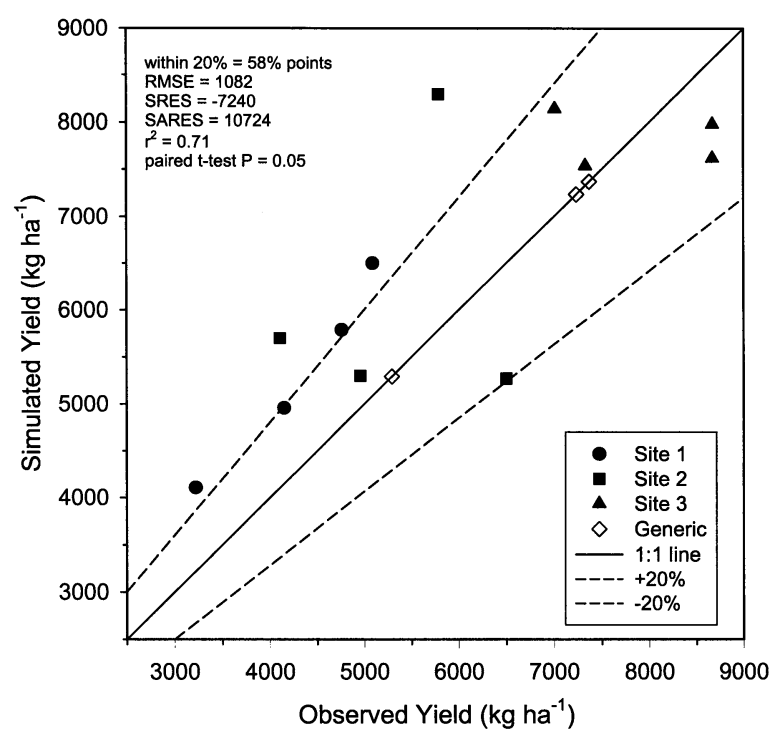

Fig. 3. Observed vs. simulated yield.

Grain yield predictions were not as good as growth stage predictions, although the $r^{2}$ was 0.71 (Fig. 3). Model bias was towards over-predicting yield at sites of Sites 1 and 2. The over-prediction of yield might be reduced if more effort is put into parameterization and increasing the accuracy of the initial conditions and driving variables. No other parameterization was done of SHOOTGRO aside from the phenological parameters and setting parameters for the maximum number of spikelets and florets per spikelet expected by agronomists from the region. The validation data set also was missing information for some initial inputs (soil and water parameters). Given the considerable difference between cultivars and growing conditions between the Central Great Plains of the US and Czech Republic, the yield simulations results are quite good.

\subsection{Sensitivity analysis}

\subsubsection{Phenological parameters}

Changing the thermal estimates between various growth stages resulted in low mean sensitivity indexes for almost all output variables (including those not shown in Table 2 such as above ground biomass, number of culms and spikes produced, harvest index, and maximum LAI), regardless of site. For all phenological parameters changed (including those not shown in Table 2 such as the thermal time between jointing and booting, booting and heading, and heading and anthesis), the only output variable showing any significant model sensitivity was the date of physiological maturity to changing the thermal time for grain filling (MATPA).

Analysis of individual sensitivity index calculations for each incremental change in the thermal estimates did not identify any unusual patterns (data not shown). Using MATPA (number of GDD from anthesis to physiological maturity) to illustrate the most unusual pattern, the individual sensitivity index for all three sites usually was within $0.2-0.3$, with most values close to 0.25 (Fig. 4). The model was more sensitive at higher thermal estimates, although no pattern was discernable, especially when viewed across sites.

Changing phenological parameters did change the mean date that specific growth stages were reached for all stages occurring after the interval changed, as would be expected. Again using MATPA to illustrate this, the date of physiological maturity was linearly and positively related to thermal time for grain filling (Fig. 4).

Given that SHOOTGRO is not overly sensitive to changing thermal time estimates, and that we 
Table 2

Means of sensitivity index calculations for the three sites. Last three columns are qualitative assessments because index could not be calculated

\begin{tabular}{|c|c|c|c|c|c|c|c|c|c|c|c|}
\hline \multirow[t]{2}{*}{ Output variable } & \multicolumn{11}{|c|}{ Variable changed } \\
\hline & $\mathrm{SRPA}^{\mathrm{a}}$ & DRPA $^{a}$ & $\mathrm{TSPA}^{\mathrm{a}}$ & $\mathrm{JTPA}^{\mathrm{a}}$ & MATPA $^{b}$ & Sowing date & Sowing rate & $\begin{array}{l}\mathrm{N} \text { fertilizer } \\
\text { amount }\end{array}$ & $\begin{array}{l}\text { Maximum/ } \\
\text { Minimum air } \\
\text { temperature }\end{array}$ & $\begin{array}{l}\text { Initial soil } \\
\text { water }\end{array}$ & $\begin{array}{l}\mathrm{N} \text { fertilizer } \\
\text { timing }\end{array}$ \\
\hline \multicolumn{12}{|l|}{ Site 1} \\
\hline Yield $\left(\mathrm{T} \mathrm{ha}{ }^{-1}\right)$ & -0.1 & -0.01 & 0.02 & -0.1 & 0.04 & 2.58 & 0.05 & 0.12 & High & Low & High \\
\hline Emergence (DOY) & 0 & 0 & 0 & 0 & 0 & 1.35 & 0 & 0 & High & None & None \\
\hline Jointing (DOY) & 0.1 & 0.06 & 0.07 & 0.06 & 0 & -0.2 & 0 & 0 & High & None & None \\
\hline Anthesis (DOY) & 0.07 & 0.03 & 0.04 & 0.03 & 0 & 0 & 0 & 0 & High & None & Low \\
\hline Maturity (DOY) & 0.03 & 0.02 & 0.03 & 0.02 & 0.29 & -0.1 & 0 & 0 & High & None & Low \\
\hline \multicolumn{12}{|l|}{ Site 2} \\
\hline Yield $\left(\mathrm{T} \mathrm{ha}^{-1}\right)$ & -0.14 & -0.03 & -0.07 & -0.11 & 0.05 & 1.96 & 0.18 & 0.07 & High & Low & High \\
\hline Emergence (DOY) & 0 & 0 & 0 & 0 & 0 & 1.55 & 0 & 0 & High & None & None \\
\hline Jointing (DOY) & 0.11 & 0.06 & 0.09 & 0.06 & 0 & -0.13 & -0 & 0 & High & None & None \\
\hline Anthesis (DOY) & 0.05 & 0.03 & 0.05 & 0.03 & 0.02 & -0.09 & -0.02 & 0 & High & None & Low \\
\hline Maturity (DOY) & 0.04 & 0.02 & 0.03 & 0.02 & 0.23 & -0.07 & -0.01 & 0 & High & None & Low \\
\hline \multicolumn{12}{|l|}{ Site 3} \\
\hline Yield $\left(\mathrm{T} \mathrm{ha}{ }^{-1}\right)$ & -0.23 & 0.03 & 0.07 & 0 & 0.04 & 0.94 & 0.22 & 0.40 & Medium & Low & High \\
\hline Emergence (DOY) & 0 & 0 & 0 & 0 & 0 & 5.55 & 0 & 0 & High & None & None \\
\hline Jointing (DOY) & 0.08 & 0.05 & 0.07 & 0.05 & 0 & -0.58 & -0.01 & 0.01 & High & None & Low \\
\hline Anthesis (DOY) & 0.05 & 0.03 & 0.05 & 0.03 & 0 & -0.96 & -0.02 & 0.02 & High & None & Low \\
\hline Maturity (DOY) & 0.03 & 0.02 & 0.03 & 0.02 & 0.24 & -0.58 & 0 & 0.01 & High & None & Low \\
\hline
\end{tabular}

${ }^{a}$ Number of phyllochrons from 1st January to single ridge (SRPA), single ridge to double ridge (DRPA), double ridge to terminal spikelet (TSPA) and start of internode elongation to jointing (JTPA).

${ }^{\mathrm{b}}$ Number of GDD from anthesis to physiological maturity (MATPA). 

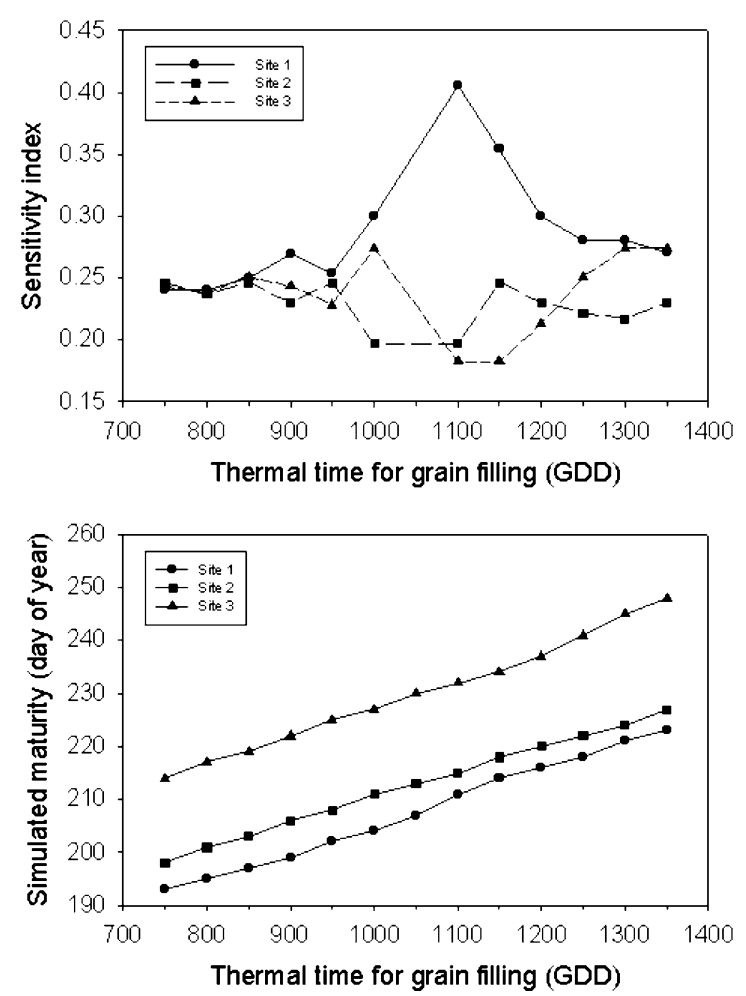

Fig. 4. Sensitivity analysis results and simulated maturity date for changing the thermal time required for grain filling (MATPA). Thermal time is the cumulative GDD using $0{ }^{\circ} \mathrm{C}$ base temperature from the start of anthesis to physiological maturity.

were able to validate the growth stages of anthesis and physiological maturity well with a few readily available parameterization data, we believe that SHOOTGRO can be readily used in the Czech Republic to predict growth stages as an aid in management decision-making.

\subsubsection{Management practices and initial conditions}

For all three sites, SHOOTGRO was most sensitive to changes in sowing date and daily temperature and insensitive to soil water in the profile at planting (Tables 2-5). Model sensitivity to sowing rate and $\mathrm{N}$ fertilizer amount and timing tended to be moderate, but was somewhat variable dependent on the site. If the model showed sensitivity to a management practice or initial conditions, predicted yield always reflected this sensitivity and was generally the variable showing the greatest response. The only exception to this generality was at Site 3, when varying sowing date or daily temperature, in which case, predicted emergence showed a greater response than yield. (The other output variables examined were above ground biomass, number of culms or spikes, harvest index, and LAI; data not shown).

Simulated yield response to different levels of management practices and initial conditions generally followed the expected pattern. For sowing date, if planting occured much before our default date, then yield was reduced (Fig. 5). At both Sites 2 and 3 yield plateaued with late planting dates, and the default date was at or near the maximum plateau. Model results indicate that planting date should be delayed a little if maximum yield is the goal for Site 1. Changing the daily temperature gave similar grain yield responses in each site: as temperature increased yield decreased (Table 3). Sowing rate had relatively little effect on grain yield at Sites 1 and 2, although the trend for all sites was a positive correlation between sowing rate and yield, with the correlation most positive for Sites 2 and 3 (Fig. 6). The results support that sowing rates are near optimum for Sites 2 and 3, and could be decreased at Site 1. Grain yield responses to $\mathrm{N}$ fertilizer amount were positively correlated, with Site 3 showing the greatest response. Our default fertilizer amount of $40 \mathrm{~kg} \mathrm{~N}$ $\mathrm{ha}^{-1}$ seems to be near optimal for Sites 1 and 2, and a little low for Site 3 . The timing of $\mathrm{N}$ fertilizer on grain yield (Table 5) depended primarily on the total amount applied for Sites 1 and 2, with little response to timing. Although probably not a significant difference, simulated yield for all three sites was slightly greater for the split applications when the latest spring application time was used. This result suggests that delaying the second application will not negatively impact yield, but allows the producer additional time to better estimate the $\mathrm{N}$ needed based on current conditions of the crop. This will improve the likelihood of not over-applying $\mathrm{N}$, and thereby save the cost of unnecessary fertilizer and potential environmental degradation of excess N. Soil water in the profile at planting had little, if any, impact on final grain yield (Table 4). There was a tendency for final grain yield to be slightly positively correlated with 
Table 3

Sensitivity analysis of changing the daily maximum and minimum air temperature from -4 to $4{ }^{\circ} \mathrm{C}$

\begin{tabular}{|c|c|c|c|c|c|c|c|c|c|}
\hline \multirow[t]{2}{*}{ Simulated variable } & \multicolumn{9}{|c|}{ Daily maximum and minimum temperature change $\left({ }^{\circ} \mathrm{C}\right)$} \\
\hline & -4 & -3 & -2 & -1 & 0 & -1 & +2 & +3 & +4 \\
\hline \multicolumn{10}{|l|}{ Site I } \\
\hline Yield $\left(\mathrm{T} \mathrm{ha}^{-1}\right)$ & 6.10 & 5.87 & 5.79 & 5.18 & 4.68 & 4.63 & 4.82 & 4.97 & 4.66 \\
\hline Emergence (DOY) & 289 & 287 & 285 & 283 & 282 & 281 & 280 & 280 & 279 \\
\hline Jointing (DOY) & 145 & 139 & 133 & 127 & 120 & 113 & 105 & 96 & 88 \\
\hline Anthesis (DOY) & 185 & 177 & 169 & 162 & 155 & 148 & 140 & 133 & 126 \\
\hline Maturity (DOY) & 244 & 236 & 226 & 216 & 207 & 198 & 190 & 182 & 173 \\
\hline \multicolumn{10}{|l|}{ Site 2} \\
\hline Yield $\left(\mathrm{T} \mathrm{ha}^{-1}\right)$ & 7.20 & 7.45 & 6.67 & 6.98 & 6.40 & 6.18 & 6.18 & 6.30 & 6.10 \\
\hline Emergence (DOY) & 295 & 290 & 288 & 286 & 285 & 284 & 283 & 282 & 282 \\
\hline Jointing (DOY) & 149 & 142 & 136 & 130 & 123 & 115 & 107 & 97 & 89 \\
\hline Anthesis (DOY) & 191 & 183 & 174 & 166 & 158 & 151 & 143 & 135 & 128 \\
\hline Maturity (DOY) & 275 & 265 & 250 & 239 & 213 & 209 & 204 & 198 & 189 \\
\hline \multicolumn{10}{|l|}{ Site 3} \\
\hline Yield $\left(\mathrm{T} \mathrm{ha}^{-1}\right)$ & 6.78 & 6.71 & 6.53 & 7.13 & 6.51 & 6.61 & 6.36 & 6.09 & 5.59 \\
\hline Emergence (DOY) & 122 & 111 & 96 & 32 & 309 & 303 & 299 & 297 & 295 \\
\hline Jointing (DOY) & 159 & 149 & 137 & 134 & 134 & 129 & 123 & 117 & 109 \\
\hline Anthesis (DOY) & 194 & 183 & 179 & 172 & 172 & 165 & 159 & 152 & 142 \\
\hline Maturity (DOY) & 251 & 242 & 237 & 230 & 230 & 221 & 213 & 204 & 194 \\
\hline
\end{tabular}

soil water at planting. Similar results were estimated by Št'astná and Žalud (1999) with the help of the MACROS and CERES models for grain maize.

The only instances where phenological output variables showed sensitivity to management practices and initial conditions were for sowing date and changing the daily temperature. These results would be expected from field studies. Since temperature is the primary factor controlling development (McMaster, 1997), and changing the daily temperature alters the rate of thermal accumulation, phenological output variables should be affected. Delaying the sowing date has the same impact on thermal accumulation as sowing in a season with cooler temperatures in the fall so that heat units accumulate more slowly. We should note that delayed sowing, and sowing at normal dates but during a season with abnormally cool temperatures, will not have the same impact on wheat development as may be implied by the previous statement. The impact of shorter daylengths with delayed sowing on the phyllochron (shorter phyllochron) interacts with the slower rate of accumulation of thermal time, in general, to result in the interaction having less impact on wheat development than on thermal time accumulation. The reduced effect on postwinter growth stages reflects the secondary influence of fall development on post-winter phenology, especially anthesis and physiological maturity.

These results are encouraging as the management practices and initial conditions that SHOOTGRO is most sensitive to are relatively easy to determine (e.g. sowing date, $\mathrm{N}$ fertilizer rate and timing, daily temperature), while SHOOTGRO is not overly sensitive to variables that are more difficult to determine, such as initial soil water in the profile. One caveat to this generalization is that if the specific cultivar grown differs significantly from the generic cultivar used, then adjusting the 
Table 4

Sensitivity analysis of changing the initial amount of soil water in the profile at planting $(0-1.8 \mathrm{~m})$. The 'medium' values were based on several years of observed data, the 'low' values were decreasing the observed data by $10 \%$, and the 'high' values were for saturated water content

\begin{tabular}{|c|c|c|c|c|c|c|c|c|c|}
\hline \multirow[t]{2}{*}{ Simulated variable } & \multicolumn{3}{|l|}{ Site 1} & \multicolumn{3}{|l|}{ Site 2} & \multicolumn{3}{|l|}{ Site 3} \\
\hline & Low & Medium & High & Low & Medium & High & Low & Medium & High \\
\hline Emergence (DOY) & 282 & 282 & 282 & 285 & 285 & 285 & 309 & 309 & 309 \\
\hline First tiller (DOY) & 306 & 306 & 306 & 315 & 315 & 315 & 104 & 104 & 104 \\
\hline Begin stem elongation (DOY) & 113 & 113 & 113 & 115 & 115 & 115 & 127 & 127 & 127 \\
\hline Jointing (DOY) & 120 & 120 & 120 & 123 & 123 & 123 & 134 & 134 & 134 \\
\hline Booting (DOY) & 142 & 142 & 142 & 145 & 145 & 145 & 158 & 158 & 158 \\
\hline Heading (DOY) & 150 & 150 & 150 & 154 & 154 & 154 & 167 & 167 & 167 \\
\hline Anthesis (DOY) & 185 & 185 & 185 & 158 & 158 & 158 & 172 & 172 & 172 \\
\hline Physiological maturity (DOY) & 207 & 207 & 207 & 213 & 213 & 213 & 230 & 230 & 230 \\
\hline Yield $\left(\mathrm{T} \mathrm{ha}{ }^{-1}\right)$ & 4.62 & 4.66 & 4.68 & 6.35 & 6.38 & 6.38 & 6.52 & 6.67 & 6.51 \\
\hline Total culms produced per $\mathrm{m}^{2}$ & 1847 & 1841 & 1843 & 1841 & 1857 & 1849 & 1285 & 1293 & 1286 \\
\hline Final number of spikes per $\mathrm{m}^{2}$ & 553 & 556 & 559 & 549 & 553 & 552 & 501 & 501 & 501 \\
\hline Harvest index & 0.42 & 0.42 & 0.42 & 0.49 & 0.45 & 0.45 & 0.61 & 0.61 & 0.61 \\
\hline
\end{tabular}

Table 5

Sensitivity analysis of changing the timing and amount of $\mathrm{N}$ fertilizer $\left(\mathrm{kg} \mathrm{K} \mathrm{ha}^{-1}\right)$. Nitrogen application was at one of three times, with the first position denoting a presowine application (DOY 271, 273 and 282 for Sites 1-3, respectively), and the second (DOY 55, 64 and 104 for Sites 1-3, respectively), and third positions (DOY 110, 125 and 139 for Site $1-3$, respectively) denoting spring applications

\begin{tabular}{|c|c|c|c|c|c|c|c|c|c|c|c|c|}
\hline \multirow[t]{2}{*}{ Simulated variable } & \multicolumn{4}{|l|}{ Site 1} & \multicolumn{4}{|l|}{ Site 2} & \multicolumn{4}{|l|}{ Site 3} \\
\hline & $40--$ & $4040-$ & 404040 & $40-40$ & $40--$ & $4040-$ & 404040 & $40-40$ & $45--$ & $4545-$ & 454545 & $45-45$ \\
\hline Emergence (DOY) & 282 & 282 & 282 & 282 & 285 & 285 & 285 & 285 & 309 & 309 & 309 & 309 \\
\hline First tiller (DOY) & 306 & 306 & 306 & 306 & 315 & 315 & 315 & 315 & 108 & 108 & 105 & 105 \\
\hline Begin stem elongation (DOY) & 113 & 113 & 113 & 113 & 115 & 115 & 115 & 115 & 127 & 127 & 128 & 128 \\
\hline Jointing (DOY) & 120 & 120 & 120 & 120 & 123 & 123 & 123 & 123 & 134 & 134 & 136 & 136 \\
\hline Booting (DOY) & 142 & 142 & 143 & 143 & 145 & 145 & 146 & 146 & 157 & 157 & 159 & 159 \\
\hline Heading (DOY) & 150 & 150 & 151 & 152 & 154 & 154 & 155 & 155 & 167 & 168 & 168 & 168 \\
\hline Anthesis (DOY) & 155 & 155 & 156 & 156 & 158 & 358 & 160 & 160 & 171 & 172 & 173 & 173 \\
\hline Physiological maturity (DOY) & 207 & 207 & 208 & 208 & 213 & 213 & 214 & 214 & 229 & 233 & 230 & 230 \\
\hline Yield $\left(\mathrm{T} \mathrm{ha}^{-1}\right)$ & 4.44 & 5.36 & 5.43 & 6.05 & 6.4 & 7.1 & 8.27 & 7.31 & 5.17 & 6.51 & 7.89 & 6.68 \\
\hline Total culms produced per $\mathrm{m}^{2}$ & 1771 & 2051 & 2051 & 1843 & 1852 & 2033 & 2033 & 1852 & 1286 & 1286 & 1334 & 1334 \\
\hline Final number of spikes per $\mathrm{m}^{2}$ & 544 & 592 & 612 & 583 & 552 & 585 & 616 & 571 & 501 & 501 & 501 & 501 \\
\hline Harvest index & 0.43 & 0.40 & 0.39 & 0.41 & 0.45 & 0.44 & 0.45 & 0.45 & 0.60 & 0.61 & 0.58 & 0.57 \\
\hline
\end{tabular}



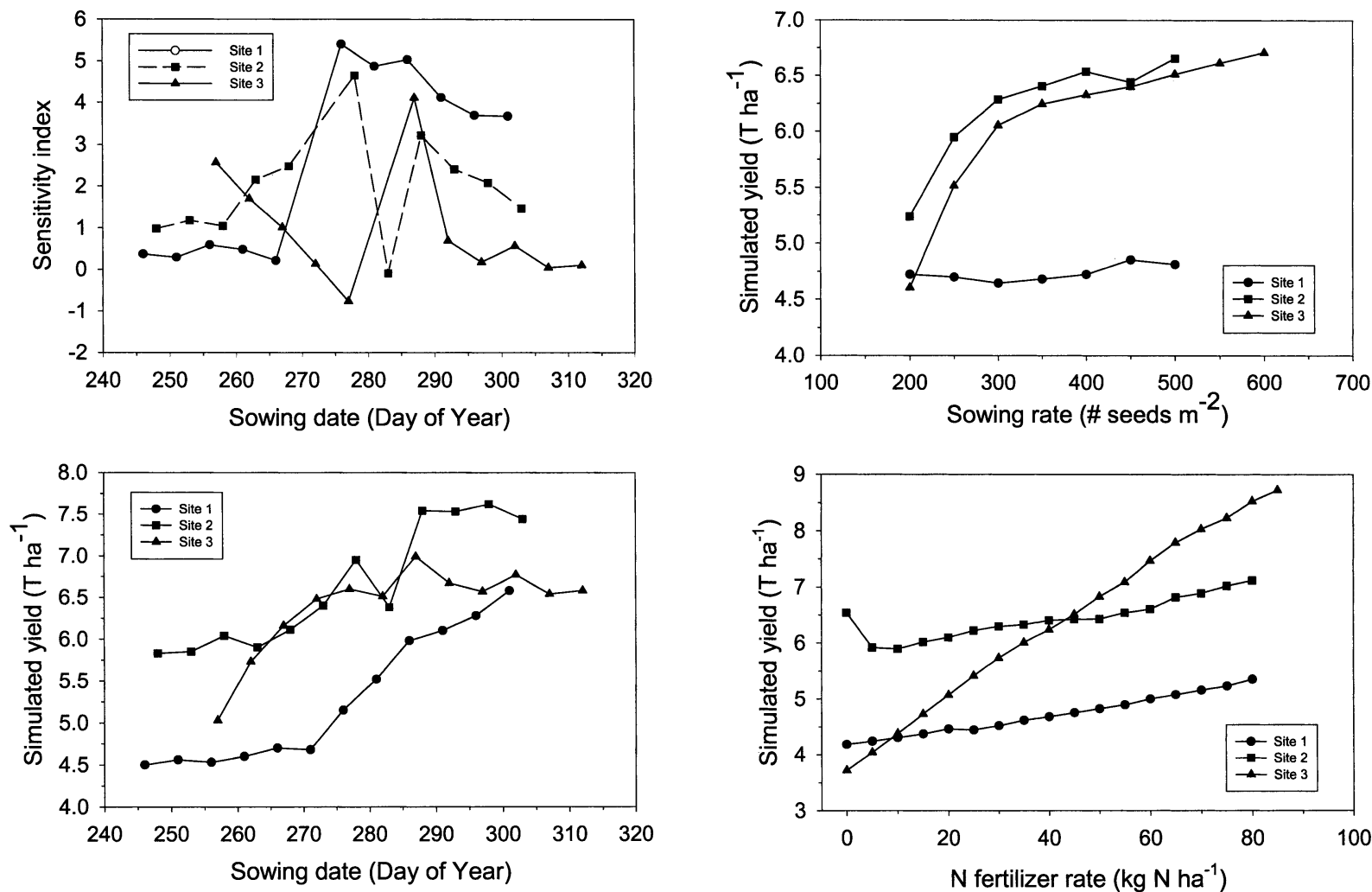

Fig. 5. Sensitivity analysis results for changing the sowing date on grain yield. The mean of the sensitivity index is given in Table 2 .

default parameters becomes more important for accurate simulation. This is more important for yield prediction than phenology because the developmental sequence is remarkably similar for most widely used cultivars (McMaster, 1997).

\section{Conclusions}

Based on this study, we believe that the developmentally-based model SHOOTGRO 4.0 can be easily parameterized and can accurately simulate phenological growth stages and grain yield in the different crop production regions of the Czech Republic. Therefore, farmers and scientists needing wheat development information to increase the efficacy of their management practices can use SHOOTGRO 4.0 as a tool to assist them.

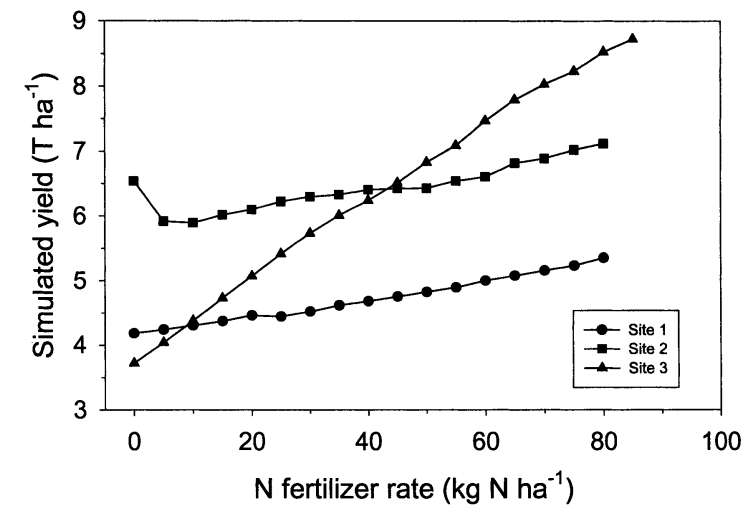

Fig. 6. Sensitivity analysis results for changing the sowing rate and $\mathrm{N}$ fertilizer amount at planting on grain yield. The means of the sensitivity index are given in Table 2 .

\section{Acknowledgements}

This study was supported in part by the Ministry of Education, Youth and Sports in the Czech Republic, research project 'Regulation of biological and technological processes for competitive agriculture' registered on Mendel University of Agriculture and Forestry Brno under No. J 08/ 98: 432100001.

\section{References}

Baker, C.K., Gallagher, J.N., Monteith, J.L., 1980. Daylength change and leaf appearance in winter wheat. Plant Cell. Environ. 3, 285-287.

Deer-Ascough, L.A., 1995. A framework for uncertainty analysis of complex process-based models. Ph.D. dissertation, University of Purdue, West Lafayette, IN, p. 156. 
Dubrovský, M., Žalud, Z., Št'astná, M., 2000. Sensitivity of Ceres-Maize yields to statistical structure of daily weather series. Climatic Change 46, 447-472.

Iglesias, A., 1995. Modelling the effects of climate change on crops at the regional scale-effects on wheat and maize in Spain. In: Harrison, P.A., Butlerfield, R.F., Downing, T.E. (Eds.), Climate Change and Agriculture in EuropeAssessment of Impacts and Adaptations. Research report No. 9, Environmental Change Unit, University of Oxford, UK, pp. 310-319.

Jamieson, P.D., Scmenov, M.A., Brooking, I.R., Francis, G.S., 1998. Sirius: a mechanistic model of wheat response to environmental variation. Eur. J. Agron. 8, 161-179.

Klepper, B., Rickman, R.W., Belford, R.K., 1983. Leaf and tiller identification on wheat plants. Crop Sci. 23, 1002 1004.

McMaster, G.S., 1993. Another wheat (Triticum spp) model? Progress and applications in crop modeling. Rivista Agronom. 27, 264-272.

McMaster, G.S., 1997. Phenology, development, and growth of the wheat (Triticum aestivum L.) shoot apex: a review. Adv. Agron. 59, 63-118.

McMaster, G.S., Smika, D.E., 1988. Estimation and evaluation of winter wheat phenology in the central Great Plains. Agric. For. Meteorol. 43, 1-18.

McMaster, G.S., Wilhelm, W.W., 1995. Accuracy of equations predicting the phyllochron of wheat. Crop Sci. 35, 30-36.

McMaster, G.S., Wilhelm, W.W., 1997a. Conservation compliance credit for winter wheat fall biomass and implications for grain production. J. Soil Water Conserv. 52, 358-362.

McMaster, G.S., Wilhelm, W.W., 1997b. Growing degree-days: one equation, two interpretations. Agric. For. Meteorol. 87, 289-298.

McMaster, G.S., Klepper, B., Rickman, R.W., Wilhelm, W.W., Willis, W.O., 1991. Simulation of aboveground vegetative development and growth of unstressed winter wheat. Ecol. Model. 53, 189-204.

McMaster, G.S., Morgan, J.A., Wilhelm, W.W., 1992a. Simulating winter wheat spike development and growth. Agric. For. Meteorol. 60, 193-220.

McMaster, G.S., Wilhelm, W.W., Morgan, J.A., 1992b. Simulating winter wheat shoot apex phenology. J. Agric. Sci. Camb. 119, 1-12.

McMaster, G.S., Ascough, J.C.H., Shaffer, M.J., Byrne, P.F., Halcy, S.D., Nielsen, D.C., Andales, A.A., Dunn, G.H., Weltz, M.A., Ahuja, L.R., 2002. Parameterizing GPFARM: an agricultural decision support system for integrating science, economics, resource use, and environmental im- pacts. In: Proceedings of International Ecological Modelling and Software Society, Lugano, Switzerland, 24-27 June, 2002.

Moot, D.J., Henderson, A.L., Porter, J.R., Semenov, M.A., 1996. Temperature, $\mathrm{CO}_{2}$ and the growth and development of wheat: changes in the mean and variability of growing conditions. Climatic Change 33, 350-368.

Rickman, R.W., Waldman, S.E., Klepper, B., 1996. MODWht3: A development-driven wheat growth simulation. Agron. J. 88, 176-185.

Ritchie, J.T., Otter, S., 1985. In: Willis, W.O. (Ed.), Description and Performance of CERES-Wheat: A User-Oriented Wheat Yield Model in ARS Wheat Yield Project. ARS38. US Department of Agriculture-Agricultural research service, pp. $159-175$.

Rožnovský, J., Svoboda, J., 1995. Agroclimatological Characterization of Žabčice Field (In Czech). Folia Universitatis agriculturae et silviculturae, Brno Res Publica Bohemica, p. 49.

Střalková, R., Pokorný, B., Šarapatka, B., Zehnálek, J., Ponížil, P., Žalud Z., 1998. Optimization of cereal nutrition for sustainable agriculture. Conclusion report of the project No. EP 7084, supported by National Agency for Agricultural Research (NAZV), p. 43 (in Czech).

Št'astná, M., Žalud, Z., 1999. Sensitivity analysis of soil hydrologic parameters for two crop simulation models. Soil Tillage Res. 50, 305-318.

Trnka, M., 1999. Climate change impacts on winter barley production, M.Sc. thesis Mendel University of Agriculture and Forestry Brno, Czech republic, p. 58 (in Czech).

Weir, A.H., Bragg, P.L., Porter, J.R., Rayner, J.H., 1984. A winter wheat crop simulation model without water or nutrient limitations. J. Agric. Sci. Camb. 102, 371-382.

Wilhelm, W.W., McMaster, G.S., 1996. Spikelet and floret naming scheme for grasses with a spike inflorescence. Crop Sci. 36, 1071-1073.

Wilhelm, W.W., McMaster, G.S., Rickman, R.W., Klepper, B., 1993. Above ground vegetative development and growth of winter wheat as influenced by nitrogen and water availability. Ecol. Model. 68, 183-203.

Wolf, J., 1993. Effects of climate change on wheat production potential in the European community. Eur. J. Agron. 2, 281-292.

Zadoks, J.C., Chang, T.T., Konzak, C.F., 1974. A decimal code for the growth stages of cereals. Weed Res. 14, 415-421.

Žalud, Z., 1999. CERES-Wheat model; possibilities of its use. Acta horticulturae et regiotecturae SPU Nitra 2, 226-230 (In Czech). 